\title{
OVERVIEW IN TREATMENT OF DEQUERVAIN DISEASE
}

\author{
Raykov D. \\ Department of orthopaedics and traumatology, "St. Anna" Hospital, Varna
}

Reviewed by: Prof. D. Boshnakov

\begin{abstract}
DeQuervain disease is tenosynovitis of extensor policis brevis and abductor policis longus muscles, passing through the $1^{\text {st }}$ ostheofibrous canal on the dorsal part of the wrist. The typical clinical complaint is painful area round radial styloid, that is increasing during strength activities of the hand and thumb. Among the popular treatment - local applications or operations for this tenosynovitis, the recent popularity of the Extracorporeal shockwave therapy becomes useful method for treatment of tendon pathology. The following study presents primary experience in application of Shockwave therapy in cases with DeQuervain disease. The success rate of $80 \%$ proves the method as a reliable and save method in treatment of this chronic tendopathy of the hand.
\end{abstract}

Key words: DeQuervain disease, tenosynovitis, Extracorporeal shockwave therapy

\section{INTRODUCTION}

The Swiss surgeon DeQuervain first described the tenosynovitis of extensor policis brevis (EPL) and abductor policis longus (APL), passing through the first ostheofibros canal of the wrist (Fig.1). Since then this complaint is popu-

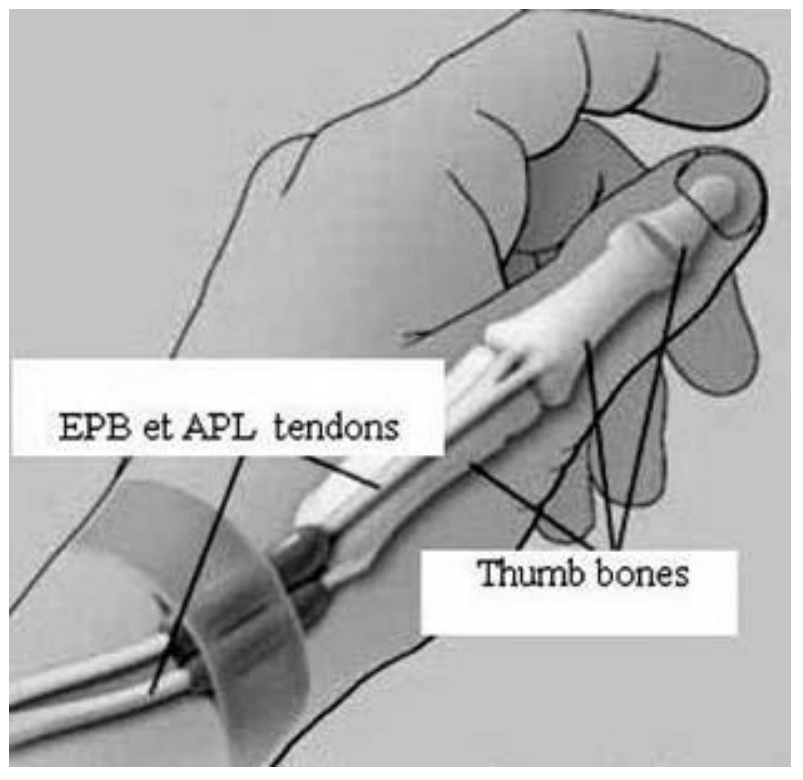

Fig. 1. Anatomy of the $1^{\text {st }}$ osteofibrous canal and the $1^{\text {st }}$ bone ray

Address for correspondence:

D. Raykov, Dept. of Orthopaedics and Traumatology

Medical University - Varna

55 "Drinov" Str., 9001, Varna, Bulgaria

e-mail: raikovortho@dir.bg lar as DeQuervain's decease. Symptoms are typical for female (age - 30-60 years), provoked by lifting activity in which the thumb is abducted and flexed, while the hand is ulnarly deviated. Activities such as inflating a blood pressure cuff, picking up a new baby out of a crib or lifting a heavy frying pan off the stove may provoke pain along the radial aspect of the wrist $(6,7)$. The following stress tests are positive and typical for the disease:

a. Filkenstein symptom- bended thumb by the examiner and ulnar tilting of the wrist (8) (Fig. 2-A).

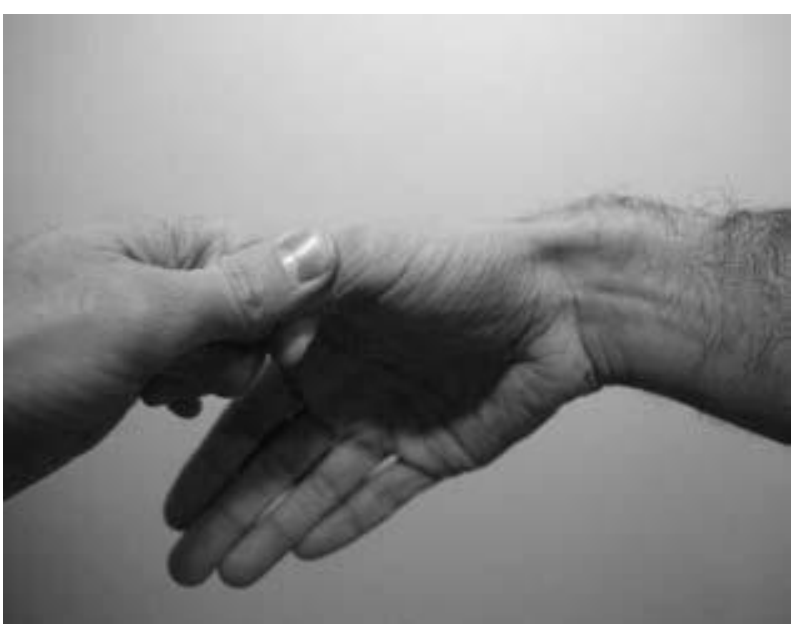

Fig. 2-A. Filkenstein test - thumb is bended by the examiner and wrist is tilted ulnarly

b. Eichoff symptom - the patient thumb is enclosed in the palm, then the wrist is deviated ulnarward by the examiner and pain is provoked (8) (Fig. 2-B). 


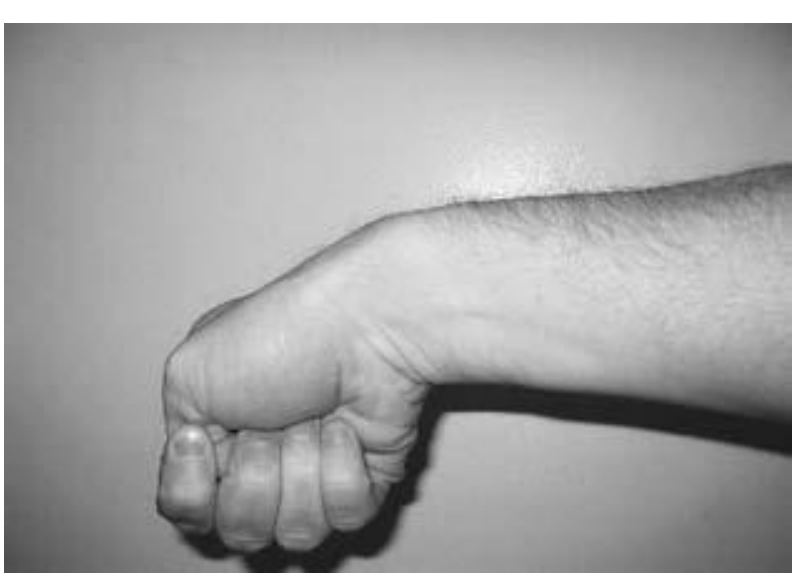

Fig. 2-B. Eichoff test - thumb is enclosed in the palm, then the wrist is deviated ulnarward by the examiner, provoking pain

The main cause of this synovithis is accepted to be over use and fatigue of the hand (1). There are some anatomical variations of the first osteofibrous canal: the first extensor compartment is divided by a septum, creating two separate tendon sheaths. Most patients with symptomatic disease have more than one abductor pollicis longus slip. These

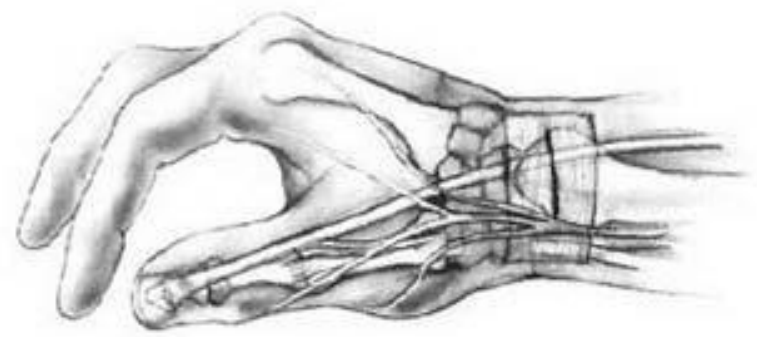

Fig. 3-A . The standard surgery approach is transverse skin incision

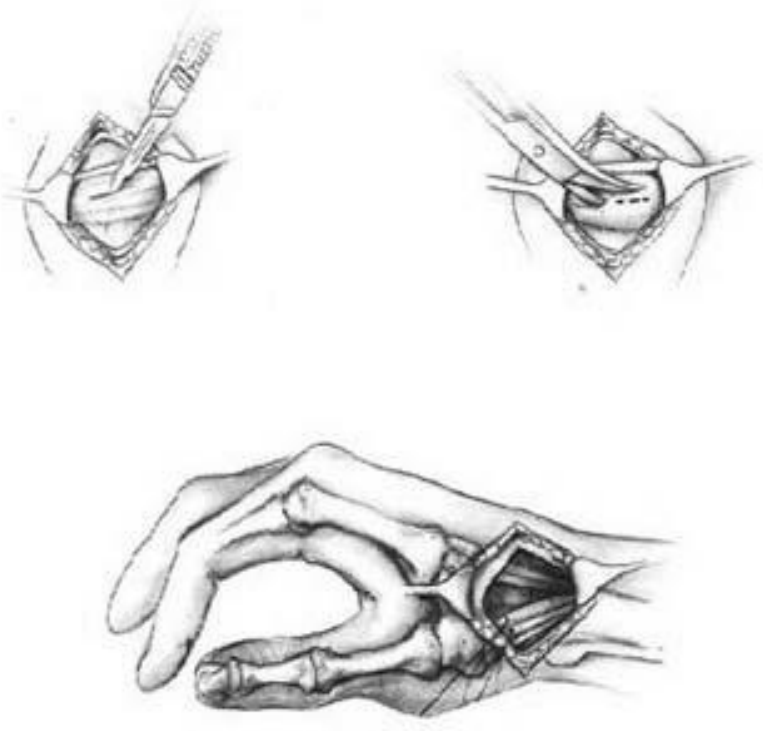

Fig. 3-B. Longitudinal cut of the synovial sheath and release of the tendons (tenolysis) variations make chronic irritation on the canal and are predisposal factors for the disease (6).

The treatment consists of conservative and surgical methods. Conservative ones are: physiotherapy, orthosis, local ointments. Local applications of corticosteroids injections are popular too with their quick pain relief, but there are few complications after their application - skin atrophy, depigmentation or neuritis of some n.radialis superficial branches (Vartenberg neuritis) (7).

The surgical treatment consists of transverse skin incision (Fig. 3-A) and longitudinal incision of the first ostheophybrous canal, followed by longitudinal cut of the synovial sheath, release of the tendons (Fig. 3-B), skin suture and early mobilization of the wrist. The above mentioned anatomical aberrations, when encountered should be corrected - each separate sheath must be opened, as each tendon slip to be tenolized. Otherwise the symptoms will relapse. There are few complications after the surgery large, rough and painful scars, neuromas and anterior dislocation of the tendons in forced wrist flexion.

Since 1992 the modification of D. Viet (7) is popular in the practice for the surgical treatment of DeQuervain tenosynovitis. It consists of transverse skin incision, release of radial nerve and superficial vein, transverse incision of first osteophybrous canal in its median part, elevation of fascial flap to its radial side. Further it is fixed to the subcutaneous layer during the skin suture. This fascial flap limits the possible anterior dislocation of the tendons.

Extracorporal shockwave therapy (ESWT) is a method with increasing popularity in treatment of several orthopedic deceases $(2,3)$. It is established in treatment of delayed bone union or nonunion, shoulder bursitis $(4,5)$, humeral epicondilitis (10), plantar fasciitis (9). There are few new fields of application, like Achilos tendopathy, trochantheritis and wound healing. Many recent studies proved the increased level of enzymes, that stimulate local tissue vascularity and thus explain its healing process (11). The aim of this study is to present the application of ESWT in treatment of DeQuervain decease.

\section{MATERIAL AND METHODS}

During the period 2007-2009 ESWT was done in a total of 10 patients (women) with clinically proved DeQuervain decease, longer than 3 months with fulfilled different treatment methods in former time - local and oral treatment with NSAD, physiotherapy, local application of corticosteroids. All patients declared unsatisfactory results. The ESWT was presented to them as noninvasive method with no side effects. They agreed to be included in treatment and to be followed up three months.

The treatment protocol is as follows:

- Device: Storz Medical Masterpuls200 (Fig.4);

- Five applications (8000 pulses each) with 5 to 7 days intervals (Fig.5);

- Applicator R20, frequency $15 \mathrm{~Hz}$;

- Pressure 1,2 Bar; 


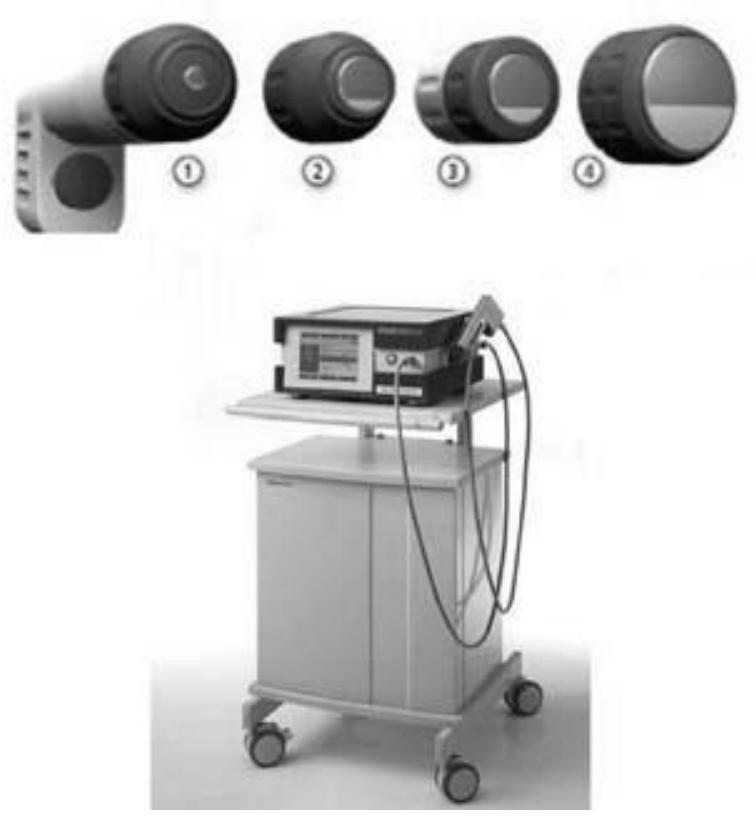

Fig. 4. Storz Medical Masterpuls 200 device with use or R20 (3)

Table 1. VAS data of pain in all 10 patients. Eight of them (80\%) got full recovery (VAS $\leq 20)$. The other two (20\%) did not get pain relief and were addressed to surgery

\begin{tabular}{|c|c|c|c|c|c|c|}
\hline Pt.No & $\begin{array}{c}\text { VAS - } 1^{\text {st }} \\
\text { procedure }\end{array}$ & $\begin{array}{l}\text { VAS - } 2^{\text {nd }} \\
\text { procedure }\end{array}$ & $\begin{array}{l}\text { VAS - } 3^{\text {rd }} \\
\text { procedure }\end{array}$ & $\begin{array}{l}\text { VAS - } 4^{\text {th }} \\
\text { procedure }\end{array}$ & $\begin{array}{l}\text { VAS }-5^{\text {th }} \\
\text { procedure }\end{array}$ & $\begin{array}{l}\text { VAS - } 3^{\text {rd }} \\
\text { month }\end{array}$ \\
\hline 1 & 55 & 52 & 42 & 31 & 21 & 11 \\
\hline 2 & 79 & 32 & 18 & 24 & 28 & 10 \\
\hline 3 & 49 & 56 & 51 & 32 & 20 & 5 \\
\hline 4 & 79 & 67 & 89 & 55 & 45 & 40 \\
\hline 5 & 56 & 32 & 45 & 11 & 10 & 0 \\
\hline 6 & 65 & 54 & 32 & 11 & 5 & 0 \\
\hline 7 & 67 & 44 & 56 & 45 & 23 & 15 \\
\hline 8 & 44 & 56 & 44 & 34 & 10 & 0 \\
\hline 9 & 76 & 65 & 44 & 34 & 23 & 12 \\
\hline 10 & 56 & 55 & 65 & 46 & 55 & 50 \\
\hline mean & 63 & 51 & 49 & 32 & 24 & 14 \\
\hline
\end{tabular}

- Contact skin gel;

- Duration of the procedure 7-8 minutes;

- Local anesthesia - not needed.

Visual analog scale (VAS) for pain (Fig.6) was used for following and assessment of the results. It was measured before each procedure ( 5 times) and on the $3^{\text {rd }}$ month.

The results after treatment of DeQuervain decease with ESWT are presented in Table 1.

Mean pain level according to VAS continues with high range until the third week ( $3^{\text {rd }}$ procedure). It is followed by

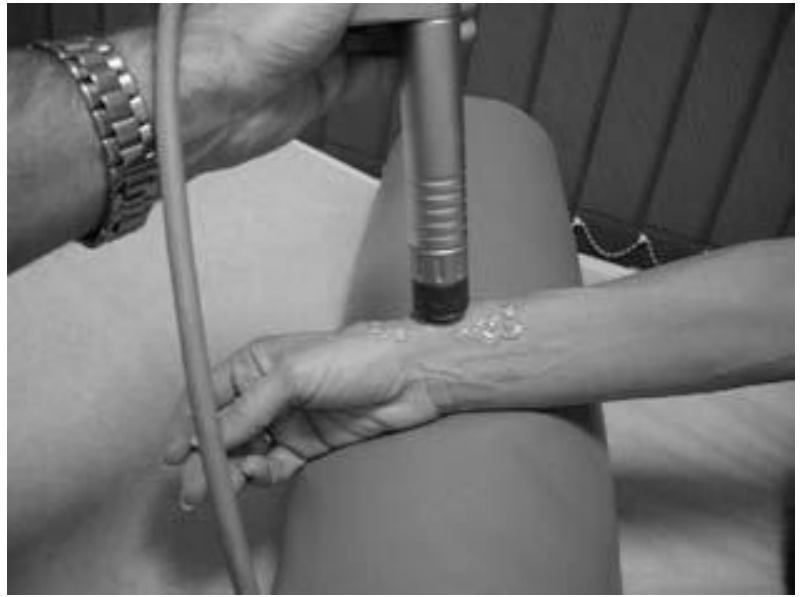

Fig. 5. Positioning of the patient's hand, while doing ESWT

significant decrease of the complains and patient satisfaction increases (Fig.7).

The good and excellent results (VAS $<20 \mathrm{~mm}$ ) were assessed in $8(80 \%)$ of our patients. The rest 2 patients presented persistent pain and were addressed to surgery. 


\section{CONCLUSIONS}

\section{PAIN SCALE}

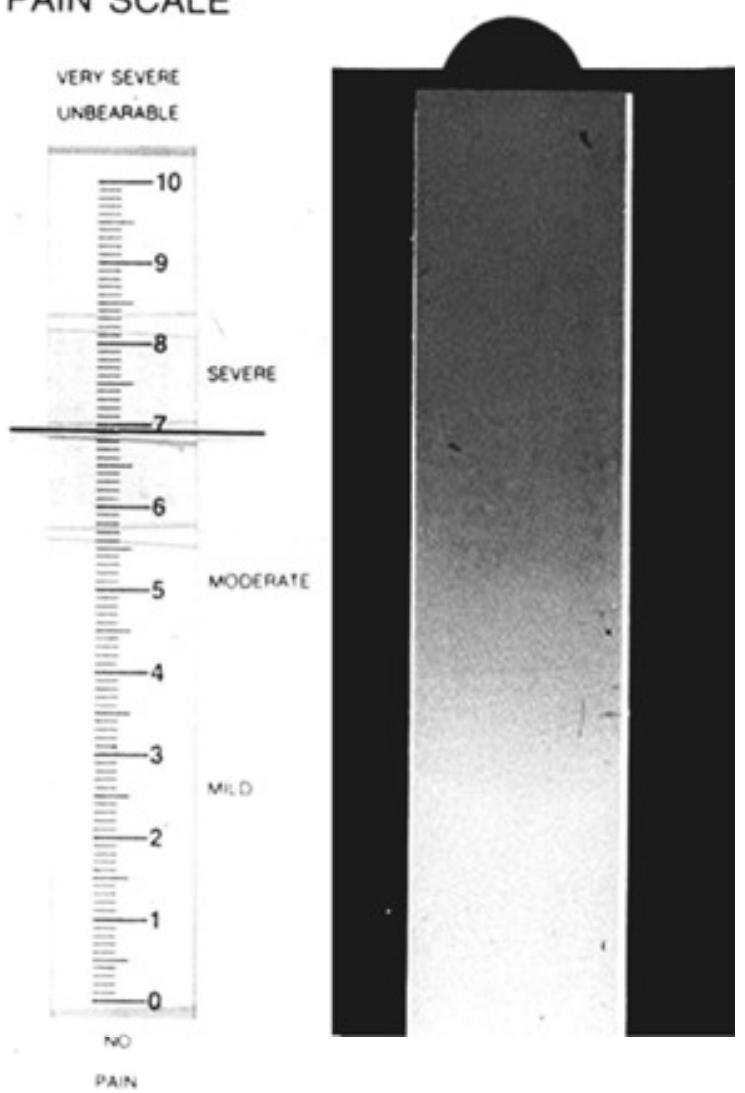

Fig.6. Visual Analog scale (VAS) for assessing pain level. Excellent and very good results $V A S \leq 20$, poor $V A S>20$.

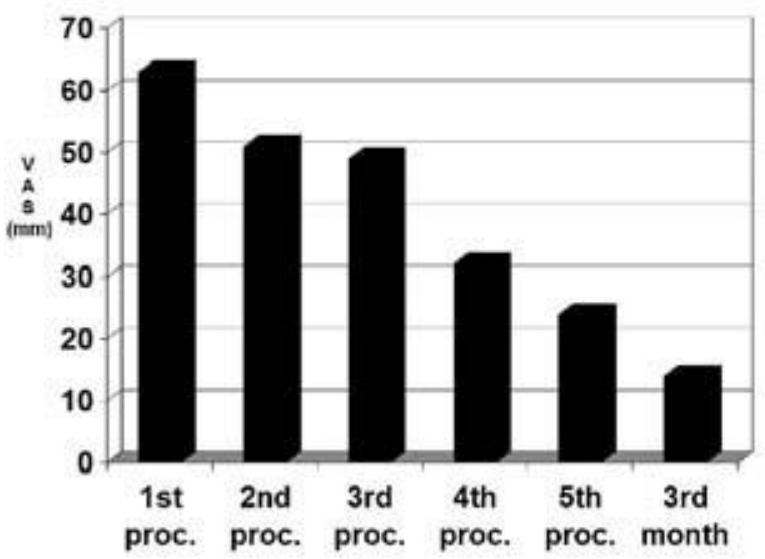

Fig. 7. Mean pain level (10 patients) according to VAS keeps high until the third week ( $3^{\text {rd }}$ procedure), followed by significant decrease of pain

There are no published studies in the orthopedic literature for the application of ESWT in treatment of DeQervain decease.
The presented study is the first one in literature regarding the application of ESWT in DeQuervain decease. The primary success rate $(80 \%)$ is similar to the results of other applications of ESWT in orthopaedics. The absence of any risks and side effects of the method and positive patient attitude makes it preferable and applicable in the daily practice. Further activities will be to aqiure bigger patient group, followed up in longer period of time.

\section{BILIOGRAPHY}

1. Burton R, Littler J: Stenosing tenovaginitis (trigger finger and trigger thumb) Curr Probl Surg 1985; 12:29

2. Chaussy C, Eisenberger F, Jocham D, et al: High Energy Shock Waves in Medicine. Stuttgart, Thieme 1997

3. Ching-Jen Wang, Feng-Sheng Wang, Kuender D. Yang MD., Biological Mechanism of Musculoskeletal Shockwaves - International society of Musculoskeletal Shockwave Therpy- ISMST NEWSLETTER 3, 2005,

4. Gremion G., Farron A., Leyvraz P. F. Efficiency of rSWT for Calcifying Shoulder Tendinitis . Extracorporeal Shockwabe therapy, Clinical results, Technologies, Basics, 2007, p.217-224

5. Loew M, Daecke W, Kuznierczak D, et al: Shockwave therapy is effective for chronic calcifying tendonitis of the shoulder. J Bone Joint Surg 81B:863-867, 1999

6. Lacey T, Goldstein L.: Anatomical and clinical studyof the variations in the insertion of the abductor pollicis longus tendon, associated with stenosing tenovaginitis. J Bone Joint Surg(Am) 1991; 33;347

7. Lister $\mathrm{G}$; The hand: Dignosis and indications $3^{\text {rd }}$ ed. Churchil Livingstone, 1993; 233-238

8. Maruyama M, Takahara M, Kikuchi N, Ito K, Watanabe T, Ogino T. DeQuervain disease caused by abductor pollicis longus tenosynovitis: a report of three cases. Hand surgery (2009) Issue: 1, Volume: 14; 43-47,

9. Ogden JA, Alvarez R., Extracorporeal Shock wave therapy for chronic plantar fasciitis. Clin. Orthop.2001, 387, 47-59

10. Rompe J., Shock wave application in Musculoskeletal Disorders p.51, 2002

11. Wang F, Yang K, Chen R, Wang C. Extracorporeal shockwave promotes growth and differentiation of bone marrow stromal cells towards osteopreogenitors associated with induction of TGFbeta1. J Bone Joint Surg 2002; 84: 457-461. 